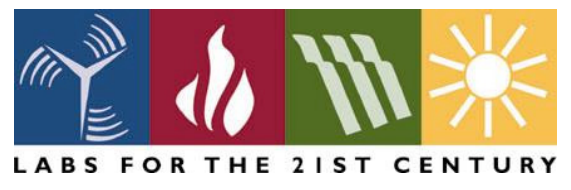

\title{
Labs21 Sustainable Design Programming Checklist Version 1.0
}

\section{January 2005}




\section{Introduction}

\section{What is this checklist?}

This checklist of sustainable design objectives and strategies can be used in the programming and conceptual design phases of a laboratory project. It includes the following:

- Brief descriptions of each objective and strategy.

- Metrics for each objective

Note that this checklist is not designed to provide detailed information on each strategy. Such information can be found via the Labs21 Design Guide, as well as the Labs21 Design Process Manual - which has the web-based version of this document, with links to detailed information resources for each strategy. Also, the Design Intent Tool has a template with the same content. All these tools are available at http://www.labs21century.gov/toolkit/index.htm.

\section{Who should use this checklist?}

This checklist is primarily to be used by owners, architects and engineers during the programming and conceptual design phase of a project. It is especially appropriate for use in design charrettes. The strategies and metrics can be included as requirements in the programming document or can be identified for further analysis or consideration during the design development phase.

\section{Checklist structure}

This checklist is hierarchically organized into design areas, objectives for each design area, and strategies and metrics for each objective. The design areas generally correspond to the design areas of the LEED ${ }^{\mathrm{TM}}$ rating system from the U.S. Green Building Council.

Two versions of the checklist are provided in this document:

- Summary: This contains the titles of the objectives and strategies for each design area.

- Expanded version: This contains the titles and descriptions of the objectives, strategies and metrics for each design area.

Please direct questions and comments to:

Paul Mathew, Lawrence Berkeley National Laboratory

email: PAMathew@lbl.gov; voice: 202-646-7952 


\section{Labs21 Sustainable Design Programming Checklist - Summary}

\section{Whole Building}

Objective: Minimize overall building energy use

Strategies:

- See specific objectives and strategies under Energy, Water, etc.

Objective: Minimize overall environmental impact

Strategies:

- See specific objectives and strategies under Energy, Water, etc.

Objective: Reduce overall life-cycle cost

Strategies:

- Use life cycle cost tools such as BLCC.

\section{Sustainable Sites}

Objective: Minimize impacts of effluents

Strategies:

\ Modeling of airborne releases

- Post-construction testing \& certification of airborne releases

๑ Effluent minimization and mitigation

\section{Water Efficiency}

Objective: Minimize laboratory water use

Strategies:

\ Potable water use reduction in laboratory equipment

a Process water conservation in laboratories

\section{Energy-Loads}

Objective: Minimize loads

Strategies:

- Optimize ventilation requirements

\ Minimize simultaneous heating and cooling loads

\ Daylighting in lab spaces

\ Right-size laboratory equipment load

\ High-performance envelope

\ Optimize temperature and humidity requirements 


\section{Energy-HVAC}

Objective: Maximize ventilation efficiency

Strategies:

Efficient fumehoods

- Specify efficient fans, motors, drives

\ Low pressure-drop system

- Manifolded and multi-stack exhaust system

口Ventilation system control strategies

Objective: Maximize cooling efficiency

Strategies:

\ Energy Recovery

- Efficient chiller systems - electric chillers, pumps, piping

Efficient chiller systems - cooling towers

․ Efficient chiller systems - Non-electric chillers

- Efficient chiller systems - Optimize chiller sizing and configuration

- Efficient chiller systems - Evaporative condenser

- Efficient chiller systems - Water-side economizer

\ Thermal energy storage

\ Evaporative cooling

口 Desiccant dehumidification

Objective: Maximize heating efficiency

Strategies:

- Efficient boiler systems - Specify efficient boilers

- Efficient boiler systems - Optimal boiler sizing and configuration

- Waste water heat exchangers

- Gas-driven humidification

- Variable flow pumping

a Controls

\section{Energy-Lighting}

Objective: Maximize lighting efficiency

Strategies:

- Efficient electrical lighting - Optimal configuration and control

- Efficient electrical lighting - Lamps and fixtures 


\section{Energy - Commissioning, Operations and Maintenance}

Objective: New construction commissioning

Strategies:

a Commissioning - Installation verification

\ Operational Assessment

- Performance measurement and verification

Efficiency Assurance

口 Appoint EMCS Coordinator

Objective: Control peak loads

Strategies:

a Load management controls

Objective: Retro-commissioning

Strategies:

口 See "performance measurement and verification" and "efficiency assurance" under new-construction commissioning

\section{Energy - Supply}

Objective: Maximize renewable energy use

Strategies:

- Photovoltaic Systems

口 Wind turbines

a Purchase electricity from renewable energy sources

Objective: Maximize energy supply efficiency

Strategies:

\ Reciprocating engine-generators

\ Turbine engine-generators

Fuel Cells

\section{Energy - Electrical Equipment}

Objective: Maximize laboratory equipment efficiency

Strategies:

\Specify energy efficient lab equipment

a Configure equipment to minimize heat gain

Objective: Minimize electric distribution losses

Strategies:

․ Efficient transformers 
a Highest practical voltage (277 V lights, etc.)

- Upsize wiring

口 Power factor correction

․ Electronic overloads in motor starters

\section{Indoor Environmental Quality}

Objective: Maximize environmental health and safety

Strategies:

a Room Pressure control

\ Modeling to optimize indoor air flow

口 Fume hood commissioning

口 Self-identifying and failsafe alarm systems

口 Displacement ventilation in lab spaces 


\section{Labs21 Sustainable Design Programming Checklist - Expanded Version}

\section{Whole Building}

\section{Objective: Minimize overall building energy use}

Energy efficiency is reducing energy consumption to achieve a given task.

\section{Strategies:}

See specific objectives and strategies under Energy, Water, etc.

\section{Metrics:}

- Site BTU/sf-yr:

Total site energy use (electrical + fuel) per gross square foot of building

- Source BTU/sf-yr:

Total source energy use (electrical + fuel) per gross square foot of building

- Energy Utility \$/sf:

Total energy cost (electricity + fuel) per gross square foot of building

口 $\mathrm{kWh} / \mathrm{sf}-\mathrm{yr}$ :

Total annual electrical energy use per gross square foot of building

口 Peak W/sf:

Peak electrical load per gross square foot of building

\ Energy effectiveness:

Ratio of ideal case BTU/sf to actual BTU/sf

口 \% Below ASHRAE 90.1:

Energy use as a percentage reduction from ASHRAE 90.1 baseline

\% Below CA Title 24:

Energy use as a percentage reduction from California Title 24 baseline

\section{Objective: Minimize overall environmental impact}

Reduce overall environmental impact on the air, land, and water through energy efficiency, material conservation, water conservation, waste reduction, and pollution prevention. See specific objectives and strategies in each design area

\section{Strategies:}

See specific objectives and strategies under Energy, Water, etc.

\section{Metrics:}

- EPC/LEED rating:

The USGBC's LEED rating system is a point-based scale that can be used to assess overall environmental "score". The Labs21 Environmental Performance Criteria (EPC) builds on the LEED rating system, by adding criteria specific to the environmental sustainability of laboratories. EPC credits may be used to get "innovation" points under the LEED system. 
The life-cycle cost of a building is its total cost over its entire life, including design, construction, operation, maintenance, renovation, and decommissioning; future costs are discounted to present value for comparison. Minimizing life-cycle costs usually results in higher first costs and lower operating costs than are common for typical buildings.

\section{Strategies:}

- Use life cycle cost tools such as BLCC.

\section{Metrics:}

․ Life-cycle $\$ /$ sf-yr:

Life-cycle cost in \$/sf-yr amortized over the life-cycle term 


\section{Sustainable Sites}

Sustainable sites includes strategies to reduce the impact of the building on the site and its surrounding natural environment.

\section{Objective: Minimize impacts of effluents}

Minimize environmental, safety and health impacts of air and sanitary sewer effluents

\section{Strategies:}

a Modeling of airborne releases

Use mathematical modeling and/or physical modeling to prove compliance with all standards and generally accepted guidelines for outdoor and nearby building protection of workers and general public from airborne chemical, radioactive and biological hazards.

- Post-construction testing \& certification of airborne releases Use post-construction testing to prove compliance with all standards and generally accepted guidelines for outdoor protection of workers and general public from airborne chemical, radioactive and biological hazards.

a Effluent minimization and mitigation

1. Use effluent controls that minimize generation of waste subject to special regulations. Use filters only where justified, no fiberglass or other duct liner exposed to exhaust stream, air cleaning systems selected for low waste generation as well as effectiveness. 2. Protect municipal sewage treatment works from pollutant discharge from building operations. Apply a drain discharge restriction policy that ensures routine discharges for laboratory and maintenance operations meet the most rigorous sewer use or local limits ordinances (Clean Water Act and Resource Recovery and Conservation Act pollutants). Use removable plugs in all drains (floor, sink, cup sink, fume hood) in the building, unless the drains are in regular use. Do not use liquid plugs for drains with infrequent use. Take steps to prevent accidental discharges to drain, such as raised lips around cup sinks, working over trays or using other methods of secondary containment. 


\section{Water Efficiency}

Water efficiency includes strategies to reduce water use and waste water generation

\section{Objective: Minimize laboratory water use}

Minimize the potable water used and waste water generated for laboratory equipment and processes

\section{Strategies:}

- Potable water use reduction in laboratory equipment Do not use "once-through" domestic water for any laboratory equipment, unless it is needed as direct contact process water. (Direct contact process water is defined as any water which, during use, comes into direct contact with any raw material, product, or waste.)

1. Use closed-loop cooling water for equipment cooling instead of open-loop (once through).

2. Use non-potable water sources.

3. Use vacuum pumps instead of aspirator fittings at cold-water faucets.

- Process water conservation in laboratories

1. Treat process wastewater so that it can be reused in cooling towers, etc.

2. Apply segregation (especially in baths) so that materials are separated from process water.

3. Work with scientists and researchers to modify process to reduce water use (if feasible and does not interfere with science).

- Efficient cooling tower operation (eliminate excessive blowdown, don't operate tower fans or pumps without load, don't overcool water (consistent with optimal chiller plant operation)

\section{Metrics:}

- Gal/sf-yr

Gallons of potable water use per unit gross area

a Gal/labsf-yr

Gallons of process water use per unit lab area 


\section{Energy-Loads}

The Loads area includes elements of the building and its surroundings (envelope, lab equipment, etc.) that create or affect the loads put on the building's mechanical and electrical systems.

\section{Objective: Minimize loads}

Apply architectural solutions to minimize the overall energy loads while meeting fresh air, exhaust, heating, cooling, and lighting requirements. Ensure that requirements (e.g. number of fumehoods) are optimized and right-sized, so that HVAC and lighting systems do not have to be oversized to meet unnecessary loads.

\section{Strategies:}

a Optimize ventilation requirements

Determine minimum ventilation requirements in laboratories based on user needs, health/safety protection and energy consumption.

1. Install minimum number and size of fume hoods. Fume hood airflow requirements often dominate the ventilation load. Review research requirements to minimize the need for fume hoods.

2. Sizing ducts for some increase in the number of hoods further reduces the pressure drop in the interim and ensures that adequate future capacity will be available without creating noise and pressure drop problems. Providing duct fittings with blank-offs make future connections easy.

3. Use the smallest hood practical. Hoods should only be used for activities that require them. Review research requirements to minimize the size of hoods. Smaller hoods have lower first and operating costs and take up less space.

4. Use glove boxes, since they have no open sash, have significantly lower airflow requirements than fume hoods.

- Minimize simultaneous heating and cooling loads

Simultaneous heating and cooling typically occurs when there is a central cooling coil in the air-handler and reheat coils at the zones. Since lab buildings use large amounts of outside air, reducing this situation is key to reducing cooling loads.

1. System configuration. The most effective way to minimize simultaneous heating and cooling is to eliminate it by using cooling coils at the zones. The air-handler has a preheat coil only or (in hot climates) may have a cooling coil for tempering.

2. Controls can greatly decrease simultaneous heating and cooling (e.g. resetting the supply air temperature from the air-handler up until the most-demanding (cooling) zone is just satisfied.)

- Daylighting in lab spaces

Daylighting can effectively be used in lab spaces to reduce electrical lighting energy use and improve visual quality.

- Right-size laboratory equipment load

Right-sizing lab equipment load will prevent oversizing of HVAC equipment.

a High-performance envelope

High performance facades can minimize undesirable heat gains and losses while providing natural light and ventilation.

1. Thermal insulation in the floor, walls, and ceiling or roof reduces conductive heat 
transfer.

2. High performance glazings and assemblies can minimize undesirable heat gains and losses while providing natural light and ventilation.

3. A tight shell and tight internal partitions (walls, doors, and floors) allow desired pressure differentials to be achieved with less differential airflow.

4. Good vapor barriers are needed to keep insulation dry and to minimize vapor migration to and from humidity controlled spaces.

5. Increasing the solar reflectivity (or "albedo") of the exterior surfaces of the building reduces the cooling load.

- Optimize temperature and humidity requirements

Select temperature and humidity setpoints to meet actual requirements of lab functions.

Metrics:

- Metric: Peak lab-only exhaust cfm/NSF

This is the lab exhaust airflow under peak conditions, expressed in cfm per net square foot of lab area.

- Peak sf/ton

Peak cooling load in gsf/ton 


\section{Energy-HVAC}

The HVAC system includes ventilation systems, cooling systems, and heating systems.

\section{Objective: Maximize ventilation efficiency}

First, minimize the ventilation loads (see "Energy- Loads")

The mechanical ventilation system consists of air-handling units (fans, filters, heating and/or cooling coils, etc.), supply ductwork, terminal devices for controlling temperature and/or pressure in the zones, exhaust and return-air ductwork, exhaust fans and exhaust stacks. A high ventilation efficiency (i.e.a low ventilation energy per square foot of building) is achieved by maximizing both the full and part-load ventilation efficiencies.

\section{Strategies:}

- Efficient fumehoods

1. Variable-volume hoods intentionally vary the exhaust air flow to maintain constant face velocity at any sash position. Lowered sashes thus result in reduced air flows.

2. Use high-performance hoods (Berkeley hood, etc.), since they use less exhaust air than standard hoods yet provide equal or better containment.

- Specify efficient fans, motors, drives

1. Efficient fans (typically airfoil or vaneaxial) convert more of the input shaft power to flow and pressure in the airstream. In addition to the fan itself, the inlet and discharge conditions are critical to good fan performance.

2. Although motors are relatively efficient converters of electrical to mechanical energy, choosing the most-efficient motor for the application is typically very cost-effective. DOE maintains the "MotorMaster" database of motor efficiency, which is valuable for making motor selections.

3. Mechanical drives include belts, couplings, shafts, and gearboxes. Cogged or synchronous belts are more efficient than standard V-belts. With variable-speed inverters (VFDs or ASDs), many applications can be driven directly, eliminating belt energy losses and maintenance altogether.

4. With variable-volume systems, the most efficient way to vary fan capacity is by varying the fan speed, rather than using variable inlet vanes or discharge dampers. The most efficient way to vary fan speed is by using a variable-frequency drive (VFD) on the electrical feed to the fan motor.

Low pressure-drop system

The power required to move air through a system is proportional to the product of the air flow and the pressure drop. Once the air flow requirements are minimized (see sections on load reduction), there are major opportunities to improve efficiency by reducing pressure drops throughout the ventilation system.

1. Filter pressure drop can be reduced through reduced face velocity and careful selection of the number of filters and their filtration efficiency.

2. Coils may be in air-handling units, zones, and exhaust (for heat recovery). In addition to increasing coil face area, low pressure drops may be achieved by using bypasses, separate fan coils, radiant heating, and zonal cooling.

3. Low duct pressure drops can be achieved by increased duct area, straighter and shorter duct runs, and low-loss fittings.

4. Throttling devices (dampers or air valves) to regulate the supply and exhaust from lab 
rooms should be selected to minimize pressure drop while still providing effective control.

- Manifolded and multi-stack exhaust system

1. Manifolded exhaust systems combine the exhaust from multiple hoods or lab areas into a common exhaust system with fewer exhaust fans. This scheme takes advantage of diversity, reducing the average duct pressure drop.

2. On VAV exhaust, multi-stack exhaust systems use two or more staged exhaust fans to maintain required discharge stack velocities without the need to introduce large amounts of bypass air.

- Ventilation system control strategies

1. Demand- controlled ventilation. Using carbon dioxide (CO2) sensors as a proxy for air quality allows the air flow to be reduced when occupancy is below design levels.

2. Occupied/unoccupied ventilation control. When rooms are unoccupied, ventilation rates can be reduced.

3. Variable-volume temperature control reduces air flow when the cooling load is below design and saves ventilation energy compared to a constant-volume design. Controls should be set up to reset the supply fan speed to just satisfy the most-demanding zone.

\section{Metrics:}

a Total annual ventilation $\mathrm{kWh} / \mathrm{sf}$

The sum of the electrical energy $(\mathrm{kWh})$ used for all ventilation systems (supply, exhaust, return, lavatory, etc.) divided by the gross building area (gsf).

a Peak total (all fans) W/cfm

The sum of the electrical power $(\mathrm{W})$ used for all ventilation fans at design conditions divided by their total design air flow (cfm).

- Supply side pressure drop (in w.g.)

Pressure drop across supply air system (AHU, heat recovery, ducts, terminal devices, etc.)

․ Exhaust/Return side pressure drop (in w.g.)

Pressure drop across exhaust/return air system (fumehoods, heat recovery, exhaust stack, etc.)

a Avg cfm/ peak cfm

The average flow of the total of all the fans (supply, exhaust, and return) divided by the total design flow of all the fans.

\section{Objective: Maximize cooling efficiency}

First, reduce the need for mechanical cooling of the building (see "Energy-Loads").

Maximizing cooling efficiency means getting the most net cooling for the input energy and power. The chiller plant consists of all of the components that supply chilled water to the building, including chiller(s), chilled water and condensing water pump(s), cooling tower or evaporative condenser, and piping, controls, and accessories.

\section{Strategies:}

․ Energy Recovery

Depending on the type of heat exchange technology used, both sensible and latent heat energy can be transferred between the intake and exhaust air, significantly reducing the heating or cooling load on the plant. 
- Efficient chiller systems - electric chillers, pumps, piping

1. Chiller efficiency is mainly a function of the chilled water and condensing water temperatures, the chiller type (centrifugal, screw, reciprocating, etc.), and the size of the evaporator and condenser.

2. Efficiently moving water through the chiller plant means minimizing the power required per gpm of water flow, both on the demand side (piping) and the supply side (pumps and motors).

2a. Efficient piping reduces pressure drops by increasing pipe diameter, making the shortest, straightest runs possible, and eliminating unnecessary components (e.g. balancing valves at coils with 2-way control valves). Lay out the piping first and let that dictate the equipment locations and pump configurations rather than the reverse.

$2 b$. Efficient pumps meet the design operating point (flow and pressure or "head") at low shaft power (bhp) requirements. Carefully selecting between size, speed and manufacturer options can pay dividends. Also look for pumps with a relatively large efficiency "bulls-eye".

- Efficient chiller systems - cooling towers (see also evaporative condenser) 1. An efficient cooling tower uses the minimum amount of fan and pump energy required to achieve the design tower water supply temperature. This means drawthrough air flow, relatively large fill and low height.

2. Variable-speed fans for cooling tower. As cooling load or outdoor wetbulb temperature decreases, the cooling tower fans can slow down while still meeting the tower water supply temperature or condenser pressure. Fan speed control, with all fans controlled together, is more efficient than two-speed control or fan staging.

- Efficient chiller systems - Non-electric chillers

1. Chiller compressors can be driven by fuel-burning engines rather than electric motors, greatly reducing peak load.

2. Absorption and adsorption chillers use heat as the input energy to produce cooling; they work on a different refrigeration cycle than the more-common compression refrigeration machines.

2a. Indirect-fired absorption and adsorption machines use heat from another source, e.g. waste heat from an engine exhaust or steam

$2 b$. Direct-fired absorption chillers burn fuel directly as a heat source.

- Efficient chiller systems - Optimize chiller sizing and configuration

1. Modular chillers use several smaller chillers instead of fewer larger chillers in order to better match chiller capacity to load.

2. Unequal-sized chillers (e.g. 1/3,2/3) can be staged to better match chiller capacity to load.

3. Variable-speed or other efficient chiller capacity modulation. Most centrifugal chiller manufacturers offer chillers than have variable-speed compressors, a more efficient modulation method than inlet vanes alone. Regardless of the technique, the important factor is a low (in $\mathrm{kW} /$ ton) APLV (Applied Part-Load Value) with the operating conditions and weighting factors appropriate for the specific building.

4. Variable-flow water pumping with variable-speed pumps. Using a variable-flow chilled water system with two-way valves and variable flow through the chiller (with local bypass if needed) is a much more efficient distribution scheme than a constant-flow chilled water system with three-way control valves. The pump speed should be controlled by a VFD to just satisfy the most-demanding zone.

5. Multi-temperature cooling plant: For buildings that have chilled water requirements at different temperatures, generating the minimum amount of colder water with one or more separate chillers will increase overall plant efficiency. 
- Efficient chiller systems - Evaporative condenser

An evaporative condenser eliminates condenser water pumps by spraying water directly on the refrigerant condensing tubes and blowing air over them. There is a small lift pump to recirculate the water as it evaporates. Typically chillers with evaporative condensers are built as a package to be installed outdoors on the roof or at ground level. The evaporative condenser takes the place of the cooling tower.

- Efficient chiller systems - Water-side economizer A water-side economizer uses a heat exchanger from the tower water to provide chilled water without using the chiller.

\ Thermal energy storage

Thermal energy storage makes use of ice or chilled water cooled during off-peak times to provide cooling during on-peak periods.

¿ Evaporative cooling Evaporative cooling is that supplied by evaporating water. The most common types are indirect, direct, and combined. In indirect evaporative cooling, air is cooled by water evaporated on the other side of a heat exchanger (or e.g. tower water is used in a cooling coil). In direct evaporative cooling, water is evaporated directly into the air, cooling and humidifying it at the same time.

- Desiccant dehumidification For humidity control applications, use of a desiccant dehumidifier can use significantly less energy than cooling and reheating the air. Desiccants adsorb the water vapor from the air and must be regenerated by heating the desiccant once it is removed from the air stream.

\section{Metrics:}

- Annual Cooling kWh/sf-yr

Total electrical energy specifically for cooling (chiller plant, any evaporative cooling, runaround coil pumps in cooling mode, etc.) divided by the gsf of the building.

a Average $\mathrm{kW} / \mathrm{ton}$

Total annual $\mathrm{kWh}$ required to provide cooling divided by the total cooling provided in ton-hours.

口 Peak W/sf

Electrical power $(\mathrm{W})$ for the entire cooling system at peak cooling divided by the building gsf.

- Peak sf/ton

Gross area of lab per ton of peak cooling capacity

- Peak $\mathrm{kW} /$ ton

$\mathrm{kW} /$ ton at design conditions

a Cooling tower performance in $\mathrm{gpm} / \mathrm{hp}$

Cooling capacity at $95 \mathrm{~F}$ entering water temperature, $85 \mathrm{~F}$ leaving water temperature, and $75 \mathrm{~F}$ outdoor wetbulb. Hp is fan motor nameplate; test procedure is CTI ATC-105 and CTI SRD-201.

口 Chiller APLV

APLV is a weighted average performance number typically based on four operating points, weighted according to their likely fraction of operation. 
First, reduce the need for heat for the building, as well as domestic and process hot water (see "Energy-Loads" and "Water Efficiency")

Maximize full and part-load efficiency of heating system. The heating system consists of all of the components that supply hot water to the building, including boiler(s) or heat pump(s), hot water pump(s), and piping, controls, and accessories.

\section{Strategies:}

- Efficient boiler systems - Specify efficient boilers

1. Condensing boilers are designed to take advantage of low-temperature (under $130 \mathrm{~F}$ ) return water to condense the water vapor from the flue gas, increasing efficiency above $90 \%$.

2. Ground-source heat pumps extract heat from (or reject heat to) the ground, using either one or more buried loops of piping or using ground water extracted and reinjected through wells.

3. Cogeneration - see "Energy Supply"

4. Modulating boilers change their firing rate to meet load. Reduced cycling means purge losses are greatly reduced.

5. Low-mass, cold-start tolerant boilers can be put into cold standby and automatically started and brought quickly up to temperature, which can greatly reduce the standby losses. Note that condensing, low-mass modulating boilers (a combination of 1, 4, and 5) increase in efficiency at part load, in contrast to conventional boilers, resulting in gas savings much larger than the difference in full-load efficiencies implies.

- Efficient boiler systems - Optimal boiler sizing and configuration Modular boilers can be staged as needed to better match boiler capacity to load, rather than cycling large boilers with high purge and standby losses.

- Waste water heat exchangers Typically, these heat exchangers are simple counterflow units that replace a section of the drain line and preheat the incoming cold water.

a Gas-driven humidification In areas that require humidity control, humidifiers that are gas-fired greatly reduce electric peak and energy consumption relative to electric steam generators.

- Pumping: variable flow with VFDs, 2-way valves, and highest-demand-zone reset (if flow and temperature are both reset, the controls must be coordinated, and ideally, optimized).

- Controls: Hot water temperature reset and system lockout based on highest-demandzone or outside air

Metrics:

a Thermal efficiency Boiler efficiency at design conditions

a Annual heating BTU/sf-yr BTU per year of site energy consumed for heating, divided by the building gsf. 


\section{Energy-Lighting}

The lighting system consists of natural and artificial light sources and distribution as well as automatic and manual controls.

\section{Objective: Maximize lighting efficiency}

First, reduce the need to illuminate areas with artificial light sources. See "Minimize Load" objective and strategies under "Energy-Loads"

Provide adequate lighting for all activities while using the minimum electricity.

Provide design-condition lighting with the minimum electrical input power.

Provide a lighting system that can efficiently meet lighting needs that are less than design light levels and number of areas.

\section{Strategies:}

- Efficient electrical lighting - Optimal configuration and control 1. Task lighting should be used to illuminate specific tasks that require elevated light levels, allowing general illumination to be at lower levels, thus providing an overall reduction.

2. Daylight harvesting controls. Controls for utilizing natural light automatically dim or switch off artificial light sources when there is adequate daylight available. Outdoor lighting controls should be combined with motion sensors or time switches.

3. Manual controls (multiple switching). Provide manual switching to allow bi-level or tri-level control, manual daylight harvesting (perimeter fixtures switch separately), and local area control to give occupants the maximum flexibility to tailor lighting levels to their needs.

4. Dimming controls. Provide manual dimming controls to allow occupants to adjust their light levels to suit the individual and task.

- Efficient electrical lighting - Lamps and fixtures

Efficient sources of electrical light generate and deliver light with a minimum of input power.

1. Fluorescent lamps with high CRI. Efficient fluorescent lamps with high Color Rendering Index may be T-8 or T-5 lamps or compact fluorescents. In general fluorescent lighting provides superior performance to High-Intensity Discharge (HID) lighting.

2. Electronic ballasts. Electronic ballasts, which themselves have low losses, drive fluorescent lamps at high frequency, increasing their efficiency. Do not use in instrument labs with sensitive equipment - use RF suppression ballasts instead.

3. Efficient luminaires. Efficient luminaires have highly reflective surfaces, good optics, and appropriate lenses to effectively deliver the light generated by the lamps to where it can be effectively used.

\section{Metrics:}

- Annual kWh/sf-yr

Total electrical energy used for indoor and outdoor lighting, divided by the building gsf.

- Peak lighting $\mathrm{W} / \mathrm{sf}$

Peak lighting load $(\mathrm{kW})$, divided by the building gsf. 


\section{Energy - Commissioning, Operation and Maintenance}

The commissioning, operation and maintenance of facilities is the continuing way that the building and its systems are run, cleaned, adjusted, and repaired. $\mathrm{O} \& \mathrm{M}$ is critical to establishing and sustaining efficient functionality.

\section{Objective: New construction commissioning}

Check that loads are met, that building systems and equipment are operating efficiently, and that automatic controls are functioning.

\section{Strategies:}

Commissioning - Installation verification

Review of drawings, specifications, submittals, and log; Construction inspection

口 Operational Assessment Testing, Adjusting, and Balancing (TAB) is typically done to ensure basic air and water flows and temperatures are per design. As building usage evolves, TAB needs to be performed to ensure new uses operate to design, and that equipment and systems continue to meet design parameters.

- Performance measurement and verification Dynamic operational measurements to ensure that systems are operating at intended performance levels. Verify that controls perform according to the sequence of operation.

\ Efficiency Assurance The International Performance Measurement and Verification Protocol specifies how to perform and record measurements of loads, equipment efficiencies, and other performance parameters.

- Appoint EMCS Coordinator The complexity of laboratory facilities is such that a person should be assigned to coordinate the operation, programming, maintenance, and modification of the Energy Monitoring and Control System (EMCS). Such individuals need to be adequately trained and not overburdened with other duties.

\section{Objective: Control peak loads}

Loads that are on during the building or utility peak can be controlled to reduce demand charges and increase supply reliability.

- Load management controls

Load management controls are specifically used to limit the peak power demand from the utility either to a set level or by a prescribed percentage. Examples of control strategies are limits on chiller loading, reduction in light levels, changes in setpoint temperature, and use of on-site generation

\section{Objective: Retro-commissioning}

Retro-commissioning provides ongoing performance assurance and can provide significant energy savings. 


\section{Strategies:}

See "performance measurement and verification" and "efficiency assurance" under new-construction commissioning

\section{Energy - Supply}

Renewable generation is electricity supplied using renewable resources as input (solar, biomass, etc.).

Energy can also be supplied from on-site cogeneration systems that use non-renewable sources more efficiently.

\section{Objective: Maximize renewable energy use}

On-site, renewable generation makes use of renewable energy available at the building site to generate electricity. The most common sources are direct sunlight or wind energy, but could include other sources such as small hydro or biomass.

\section{Strategies:}

- Photovoltaic Systems

Photovoltaic systems convert sunlight directly to direct-current electricity and connect to the alternating-current grid through an inverter. Storage batteries may be included to provide backup power but are not required for operation.

口 Wind turbines

Wind turbine generators convert wind to electricity and typically connect to the grid through an inverter.

- Purchase electricity from renewable energy sources

An alternative to generating electricity on site using renewable source is to buy it either from the local utility or have it "wheeled" from wherever it is generated.

\section{Metrics:}

๑ \% renewable energy

Fraction of the annual electricity used by the facility that is from renewable sources.

\section{Objective: Maximize energy supply efficiency}

Distributed generation places the generator at the facility using the electricity, reducing losses in the electrical grid and creating opportunities for co-generation.

\section{Strategies:}

口 Reciprocating engine-generators

Reciprocating engine generators use internal combustion engines, typically fueled by natural gas or diesel fuel, to drive electrical generators. Other fuel options include biodiesel, landfill gas, and sewage digester gas.

a Turbine engine-generators

Turbine engine generators use gas-turbine engines to drive electrical generators. The waste heat is typically at a temperature high enough to generate steam for a steam turbine (forming a combined-cycle power plant), for steam distribution, or both. 
- Fuel Cells

Fuel cells produce direct-current electricity using an electrochemical process using hydrogen (typically converted on-site from natural gas) and oxygen from the air. They are typically connected to the grid through an inverter. They have no combustion per se and thus have very low exhaust emissions beyond carbon dioxide and water. They are also quiet and have few moving parts relative to engine generators.

\section{Metrics:}

\ \% reduction in source energy use

$\%$ reduction in source energy use compared to grid supplied electricity and fuel 


\section{Energy - Electrical Equipment}

This area includes "plug-in" equipment as well as the electrical distribution system (transformers, wiring, panelboards, motor control centers, etc.)

\section{Objective: Maximize laboratory equipment efficiency}

Provide the amenity that the process requires using the least energy and peak power in the process itself and making the least demands on other building systems.

\section{Strategies:}

a Specify energy efficient lab equipment

1. EnergyStar equipment. Energy Star is a voluntary labeling program created by the EPA and DOE to promote efficient appliances, equipment, and even whole buildings. There are Energy Star labels for office equipment and appliances, water coolers, etc. 2. Enable power-management features. On office equipment, e.g. there are options to allow the equipment to automatically reduce power levels after a user-selected idle period. Ensure that these functions are turned on and set to levels that will save energy without creating significant inconvenience.

3. Workstation occupancy sensors. Motion sensors that switch some of the outlets on a power strip are available to automatically turn off expendable plug loads (monitor, task light, personal fan, etc.) in individual offices when unoccupied.

4. Automatic process controls. Processes can be equipped with automatic controls (typically time switches but thermostatic or other controls may be applicable) to operate the equipment only when needed.

5. Manual process controls. Providing (and using!) manual controls on processes can result in significant energy savings.

- Configure equipment to minimize heat gain

1. Water-cooled. Waste heat from process equipment should be removed efficiently; usually water cooling is more efficient than air cooling.

2. Reject heat at highest possible temperature. Waste heat should be rejected at the highest possible temperature (e.g. to tower water rather than chilled water), reducing cooling system energy requirements. This strategy also simplifies the system and makes it more reliable.

3. Reject air-cooled heat directly to exhaust. Where equipment is air cooled, rejecting the heated air directly to the exhaust air stream reduces the need for space cooling.

4. On refrigeration systems, use outdoor condenser. Systems that use a self-contained refrigeration cycle for cooling can use a remote condenser to reduce space-cooling requirements. A water-cooled or evaporatively cooled condenser is usually more efficient than an air-cooled one.

\section{Metrics:}

a Annual process kWh/sf-yr

The total annual process and plug load electrical energy in $\mathrm{kWh}$ divided by the total gsf of the building.

口 Process Peak $\mathrm{W} / \mathrm{sf}$

The annual maximum process and plug load electrical power in $\mathrm{kW}$ divided by the total gsf of the building. 
Reduce resistive losses in conductors and magnetic losses in transformers.

\section{Strategies:}

- Efficient transformers

Transformers have losses in their windings (load losses) and magnetic core (no-load losses), both of which can be reduced. The losses can be traded off to optimize efficiency for a given load profile.

- Highest practical voltage (277 V lights, etc.)

Where higher voltages are available (e.g. 277 volts for lighting, 480 volts for motors) their use reduces currents in conductors, reducing $\mathrm{I}^{\wedge} 2 \mathrm{R}$ losses. Note that for smaller facilities (especially once all the load reduction and efficient equipment options are in place) a single 120/208-volt transformer with right-sized wiring can be a more-efficient solution than a 277/480-volt main transformer with 120/208-volt distribution transformers.

\ Upsize wiring

Sizing wire to the Electrical Code produces a safe installation, but increasing the wire size beyond Code requirements is often cost-effective due to reduced losses.

- Power factor correction

Power factor is the ratio of "real" (useful) power in kW to "apparent" power in kVA; inductive and non-linear loads can reduce power factor, increasing the current required for a given $\mathrm{kW}$ load. Power factor correction, ideally at the load, reduces currents and thus losses in the distribution system.

- Electronic overloads in motor starters

Motor starters typically use thermal overload protection devices, which produce heat during operation. Electronic overloads reduce this parasitic loss and provide better protection for motors.

\section{Metrics:}

口 Distribution efficiency (\%)

Fraction of the annual electricity delivered at the meter that is used by the electrical loads. 


\section{Indoor Environmental Quality}

Indoor environmental quality encompasses the thermal, visual, acoustic, air, and spatial quality to maximize human comfort and productivity

\section{Objective: Maximize environmental health and safety}

Use technologies and operational strategies to ensure that people in and around the building are protected from hazardous fumes, waste, and other materials

\section{Strategies:}

口 Room Pressure control

Using technologies such as volume metering and pressure control to ensure that the appropriate pressure relationships are maintained between the laboratory space and the surrounding spaces.

- Modeling to optimize indoor air flow

Optimize indoor airflow based on results of computational fluid dynamics (CFD) or physical modeling.

- Fume hood commissioning Conduct fume hood commissioning that includes ASHRAE-110 Method of Testing Performance of Laboratory Fume Hoods, As Installed.

- Self-identifying and failsafe alarm systems Incorporate verbal warning systems, placards, and/or warning lights into alarm systems. Conduct failure mode analysis on alarm systems

口 Displacement ventilation in lab spaces A low-pressure air distribution system in which incoming air originates at floor level and rises to exhaust outlets at the ceiling. Incoming air is delivered to interior rooms by way of floor-level vents. This incoming air displaces upper air, which is exhausted through ceiling-level vents. 